\title{
Assessment of Fencing on the Orion Heatshield
}

\author{
Antonella I. Alunni* and Tahir Gökçen ${ }^{\dagger}$ \\ AMA Inc., NASA Ames Research Center, Moffett Field, CA 94035
}

\begin{abstract}
This paper presents recent experimental results from arc-jet tests of the Orion heatshield that were conducted at NASA Ames Research Center. Test conditions that simulated a set of heating profiles in time representative of the Orion flight environments were used to observe their effect on Orion's block architecture in terms of differential recession or fencing. Surface recession of arc-jet models was characterized during and after testing to derive fencing profiles used for the baseline sizing of the heatshield. Arc-jet test data show that the block architecture produces varying degrees of fencing.
\end{abstract}

\section{Introduction}

After successful completion of the Orion Exploration Flight Test 1 (EFT-1) in December 2014, the Orion program conducted various trade studies across subsystems to identify potential improvements for Orion's subsequent mission, Exploration Mission 1 (EM-1). For the thermal protection system (TPS), the program concluded that a block heatshield architecture, comprising a tiled layout of molded Avcoat blocks, would be more suitable than the monolithic heatshield consisting of honeycomb Avcoat that was flown because using molded Avcoat would facilitate greater control over processing while granting higher confidence in the performance of Orion's TPS. ${ }^{1}$

The tiled layout, which prevents adjacent blocks from contacting due to thermal expansion, requires a gap filler to inhibit heat penetration between the molded Avcoat blocks. RTV-560 was ultimately chosen as the gap filler for EM-1. However, disparate recession rates between the selected gap filler and molded Avcoat is expected to produce differential recession-revealed as fencing in the event that the gap filler recedes slower than Avcoat or gapping in the event that the gap filler recedes faster than Avcoat. Consequently, attempts at sizing the updated TPS architecture are expected to address challenges, such as heating augmentation and earlier transition to turbulence, that are brought forth by fencing or gapping at the block interfaces.

Therefore, fencing was investigated via arc-jet tests in the Aerodynamic Heating Facility (AHF) at NASA Ames Research Center (ARC). The objective of these tests was to obtain fencing profiles using flatfaced stagnation models for a wide range of transient heating conditions. This paper specifically addresses the approaches and techniques used for testing and measuring the material response of molded Avcoat with gap filler in transient flows to produce a set of fencing profiles that characterize fencing development.

\section{Test Description}

\section{A. Environments and Arc-Jet Facility}

Arc-jet tests were conducted for a total of 10 heating profiles representative of the Orion flight, which are shown in Figure 1. The five EI2 profiles that were tested have the same heat flux and pressure targets as the set of five EI6 profiles. However, EI6 profiles have a longer dwell time after the first pulse followed by a longer second pulse compared to EI2 profiles, resulting in 770-second durations for EI6 profiles and 560second durations for EI2 profiles.

\footnotetext{
* Research Scientist, MS 234-1, Member AIAA

$\dagger$ Senior Research Scientist, MS 230-2, Associate Fellow AIAA
} 

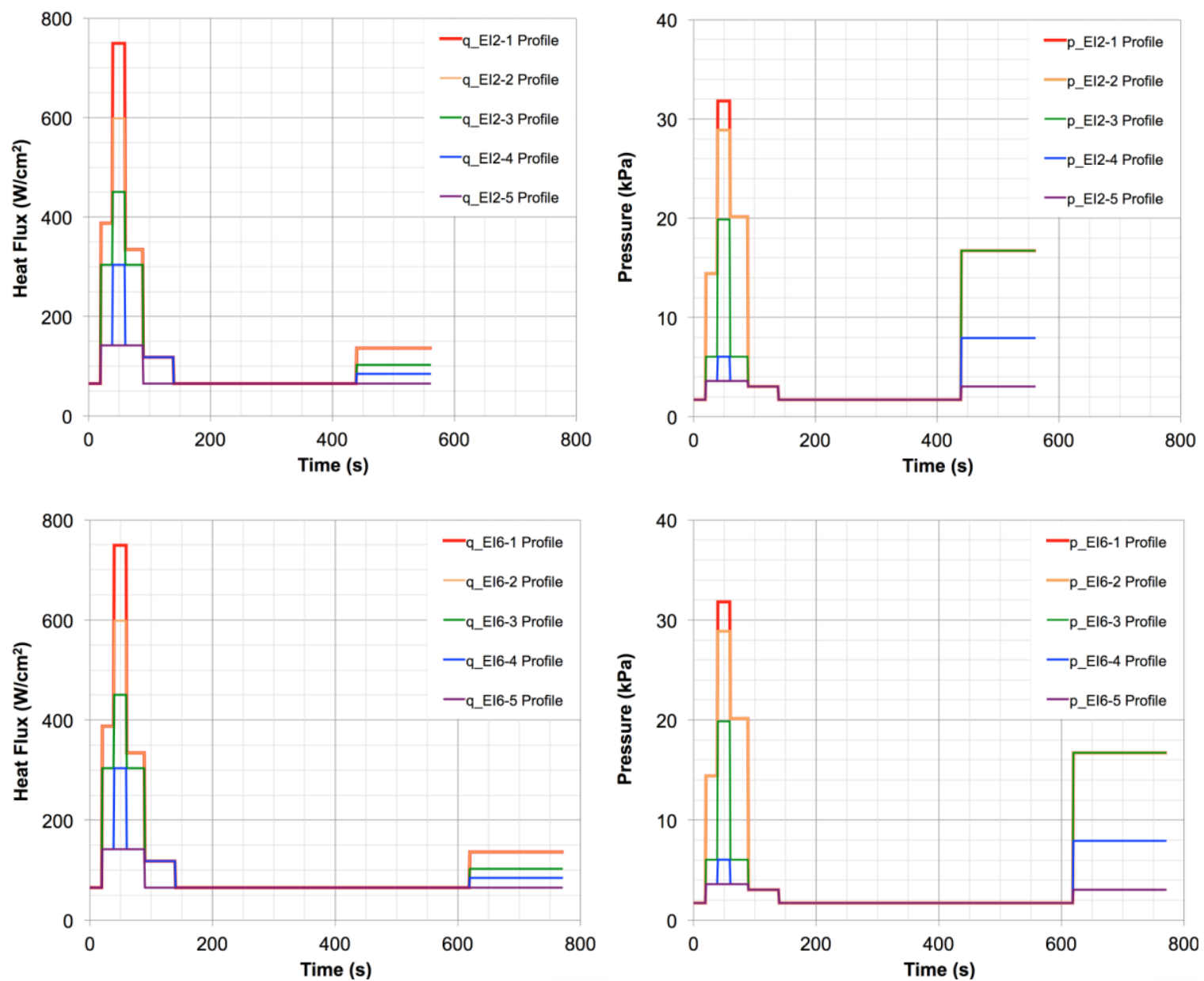

Figure 1. Full set of heat flux and pressure profiles that were tested.

The 10-MW TP3 heater was selected to operate in the AHF test chamber because of its proven ability to produce heating profiles that vary as a function of time. ${ }^{2}$ A conical nozzle with a $19.05-\mathrm{cm}(7.5-\mathrm{inch})$ diameter nozzle exit and a $5.715-\mathrm{cm}(2.25$-inch) diameter throat was used for transient testing at a wide range of facility settings. Instrumented stagnation calorimeter bodies and test articles were positioned 15.24 $\mathrm{cm}$ (6 inches) from the nozzle exit for calibration and model runs.

\section{B. Fencing Measurements}

Surface recession measurements of test articles were collected during and after model runs. The photogrammetric recession measurement (PRM) technique was used to determine surface recession across test durations for every profile, which enabled fencing rates to be evaluated for every step of each profile. PRM, an imaging method developed at NASA ARC, relies on cross-correlating images from two synchronized high-resolution video cameras to measure recession. ${ }^{3}$ Post-test fencing, determined by comparing pre-test and post-test 3-dimensional laser scans, was used to validate PRM.

\section{Results}

\section{A. Test Conditions and CFD Simulations}

Slug and Gardon gage calorimeters with a $10.16-\mathrm{cm}$ (4.0-inch) diameter, flat-face geometry were used to calibrate every profile step as a steady-state condition before running the Gardon gage calorimeter through every profile, as demonstrated for EI2-1 and EI6-1 in Figure 2. Slug and Gardon gage calibration 
data are in close agreement and within $10 \%$ of the targeted heat flux and pressure, with the exception of Step 3 of EI2-1 and EI6-1 where Gardon gage heat flux was significantly lower than slug heat flux and out of reasonable range of the targeted heat flux. Calorimeter results for the remainder of tested environments will be demonstrated similarly in the full paper.
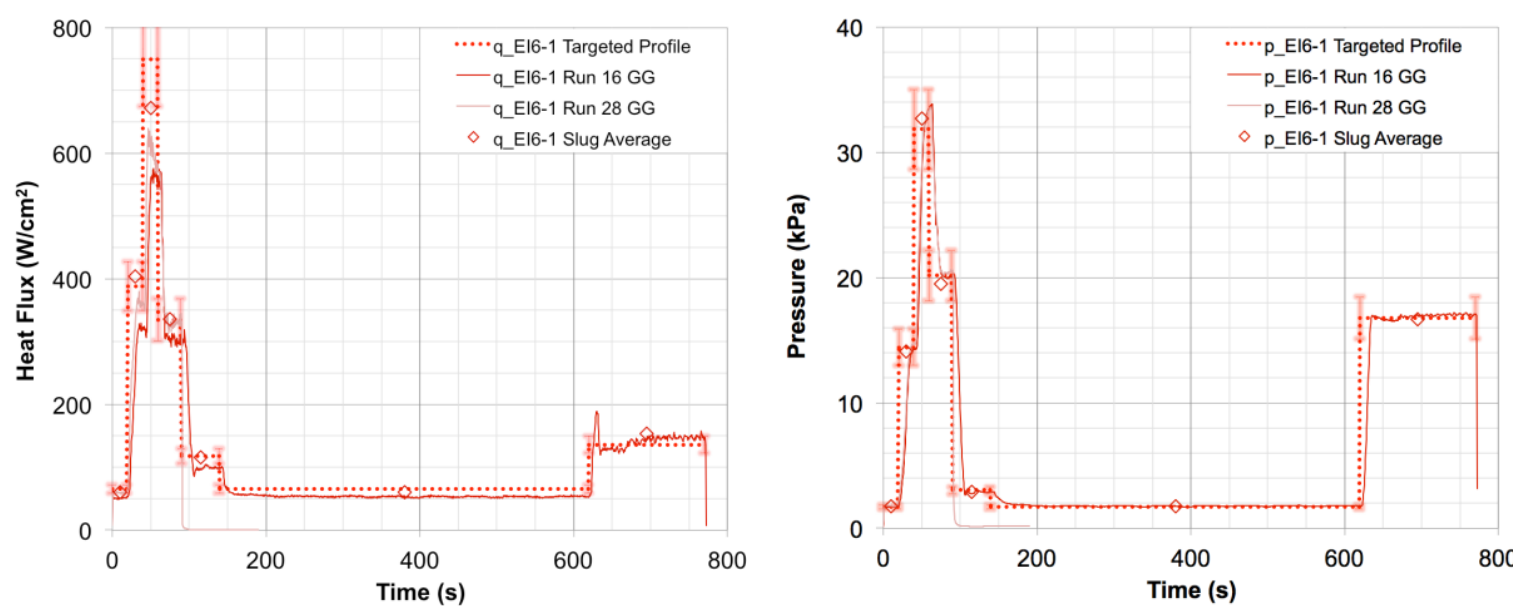

Figure 2. Heat flux and pressure calorimeter data for EI2-1 and EI6-1 (durations correspond to EI61).

Computational analyses of the TP3 arc-jet tests are performed through simulation of nonequilibrium expanding flow in the arc-jet nozzle and supersonic jet, and simulation of the flow in the test box and around the test articles. For CFD calculations presented in this paper, two-dimensional axisymmetric Navier-Stokes equations, supplemented with the equations accounting for nonequilibrium kinetic processes, are used in the formulation. The thermochemical model employed for the arc-jet flow includes five species $\left(\mathrm{N}_{2} \mathrm{O}_{2}, \mathrm{NO}, \mathrm{N}, \mathrm{O}\right)$, and the thermal state of the gas is described by two temperatures (translational-rotational and vibrational-electronic) within the framework of Park's two-temperature model. The present computational approach follows our earlier work, ${ }^{2,4}$ and it is also briefly described here. Simulations of the TP3 arc-jet facility flow are started from the nozzle inlet. The total enthalpy and its radial profile at the inlet are prescribed based on the facility and calibration data, and the flow properties at the inlet are assumed to be in thermochemical equilibrium. Measured facility data, namely, the total pressure, mass flow rate, and test box pressure, are used as boundary conditions.

The primary objective of the CFD simulations is to estimate the centerline total enthalpy of the arc-jet flow consistent with the facility and calorimeter measurements. As an illustration of a typical CFD simulation, Figure 3 shows a computed TP3 7.5-inch nozzle flowfield including the test box and a stagnation calorimeter model. In order to estimate the centerline enthalpy of the flow, uniform pressure and a nonuniform parabolic enthalpy profile are specified at the nozzle inlet such that the centerline calibration data are reproduced with the computations.

Table 1 gives an example arc-jet test for a flight heating profile simulation: its calibration and CFDestimated test environment parameters. For this case, the flight heating profile was broken into seven independent steps where each step was calibrated using flat-faced calorimeters for its centerline conditions prior to a flight profile run. Subsequently, the heating profile simulation was run in a single arc-jet run. A summary of the calibrated facility conditions including the estimated hot-wall heat flux and centerline total enthalpy values is given in Table 1 .

Further details of the computational results, CFD-estimated centerline enthalpies and hot-wall heat flux values for all heating profile runs will be included in the proposed paper. 


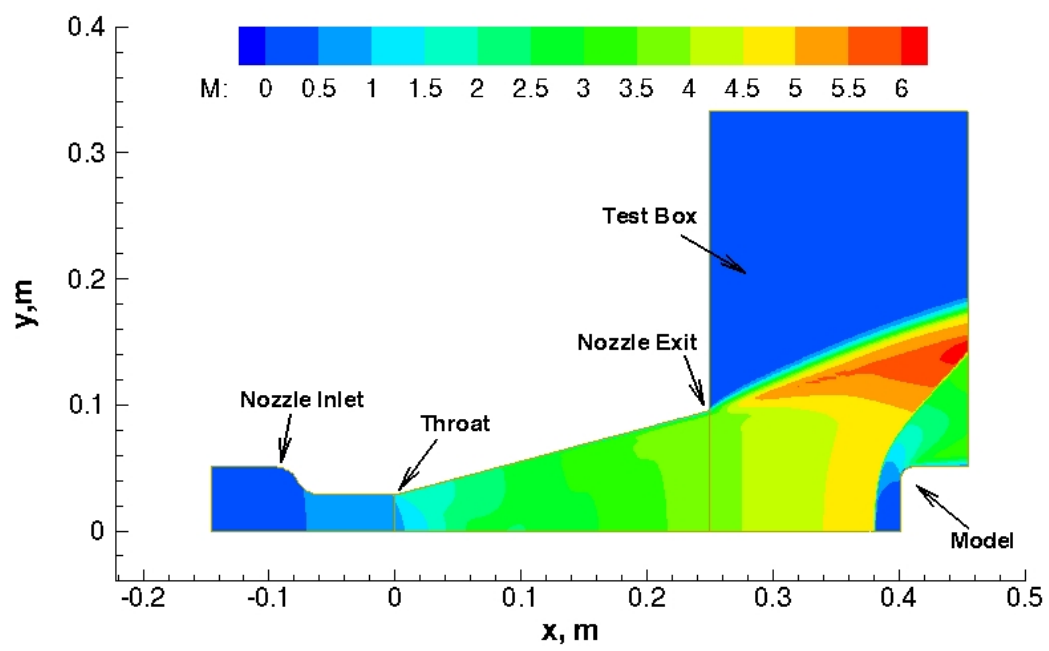

Figure 3. Computed Mach number contours of the TP3 7.5-inch nozzle flowfield including the test box and a 4-inch diameter flat-faced calorimeter model: $\dot{m}=190 \mathrm{~g} / \mathrm{s}, h_{o b}=17.6 \mathrm{MJ} / \mathrm{kg}, h_{o c l}=28.8 \mathrm{MJ} / \mathrm{kg}$.

Table 1. Summary of nominal facility conditions for a flight heating profile simulation: stagnation calorimeter data and CFD estimated parameters for the nozzle exit surveys in the TP3 7.5-inch nozzle using 4-inch diameter flat-faced calorimeters $\left(r_{c} / D=3 / 32\right)$ with data obtained at $x_{m l}=15.24$ cm.

\begin{tabular}{|c|c|c|c|c|c|c|c|c|c|}
\hline $\begin{array}{c}\text { Test Series: } \\
\text { AHF } 307\end{array}$ & $\begin{array}{c}I \\
(\mathrm{~A})\end{array}$ & $\begin{array}{c}V \\
(\mathbf{V})\end{array}$ & $\begin{array}{c}\dot{m} \\
(\mathrm{~g} / \mathrm{s})\end{array}$ & $\begin{array}{l}p_{\text {midc }} \\
\text { (kPa) }\end{array}$ & $\begin{array}{c}q_{s} \\
\left(W / \mathbf{c m}^{2}\right)\end{array}$ & $\begin{array}{c}p_{s} \\
(\mathbf{k P a})\end{array}$ & $\begin{array}{c}h_{\text {ocl }} \\
(\mathrm{MJ} / \mathbf{k g}) \\
\text { CFD }\end{array}$ & $\begin{array}{c}q_{H W F C} \\
\left(\mathbf{W} / \mathrm{cm}^{2}\right) \\
\text { CFD }\end{array}$ & $\begin{array}{c}\text { Pitot and } \\
\text { Null-Point } \\
\text { Surveys }\end{array}$ \\
\hline Runs 14-1-35-1 & 262 & 1264 & 25 & 26 & 58.6 & 1.74 & 13.8 & 51.5 & step 1, step 6 \\
\hline Runs $11-2,12-2$ & 1113 & 3401 & 190 & 220 & 388 & 14.7 & 28.8 & 349 & step 2 \\
\hline Runs 8-1, 9-1 & 1762 & 5187 & 501 & 558 & 729 & 36.0 & 34.1 & 497 & step 3 \\
\hline Runs 6-1, 7-1 & 1214 & 3946 & 310 & 311 & 335 & 21.5 & 21.9 & 292 & step 4 \\
\hline Runs 3-2, 4-1 & 419 & 1683 & 40 & 43 & 118 & 3.3 & 19.6 & 104 & step 5 \\
\hline Runs 3-3, 4-2 & 716 & 3681 & 310 & 251 & 114 & 17.0 & 9.4 & 89 & step 7 \\
\hline
\end{tabular}

\section{B. Fencing Development}

One flat-face, $10.16-\mathrm{cm}(4.0-\mathrm{inch})$ diameter, $3.81-\mathrm{cm}$ (1.5-inch) thick molded Avcoat sample with an RTV-filled gap was tested for every profile. Although each profile varied in heat flux and pressure, the overall surface response of every test article was very similar and is demonstrated by the sequence of video stills for the test article in Figure 4. During the first heat pulse consisting of Steps 1 through 5, uniform Avcoat recession was observed while the gap filler receded slightly below the Avcoat. During the dwell at Step 6, there was swelling of the silica and controlled recession away from the gap at all profiles. During the second high-pressure pulse at Step 7, excessive swelling of the entire surface was followed by rapid recession as fencing developed.

Such qualitative observations were quantified by the fencing measurements that were collected via PRM and laser scans. The PRM presented in Figure 5 illustrates that gapping occurs during the first pulse, followed by moderate fencing during the dwell and exacerbated fencing during the second pulse. PRM data are plotted against average, minimum, and maximum fence heights that were determined from laser scans. The results reveal that PRM data at the end of the test are bounded by the minimum and maximum fence heights determined from laser scans. However, average fencing by laser scans is consistently greater than fencing by PRM, which is likely due to the different selections of regions of interest used for each method. So ultimately, laser scans were used to anchor fencing rates determined by PRM to create temporal fencing profiles for heatshield sizing inputs. 


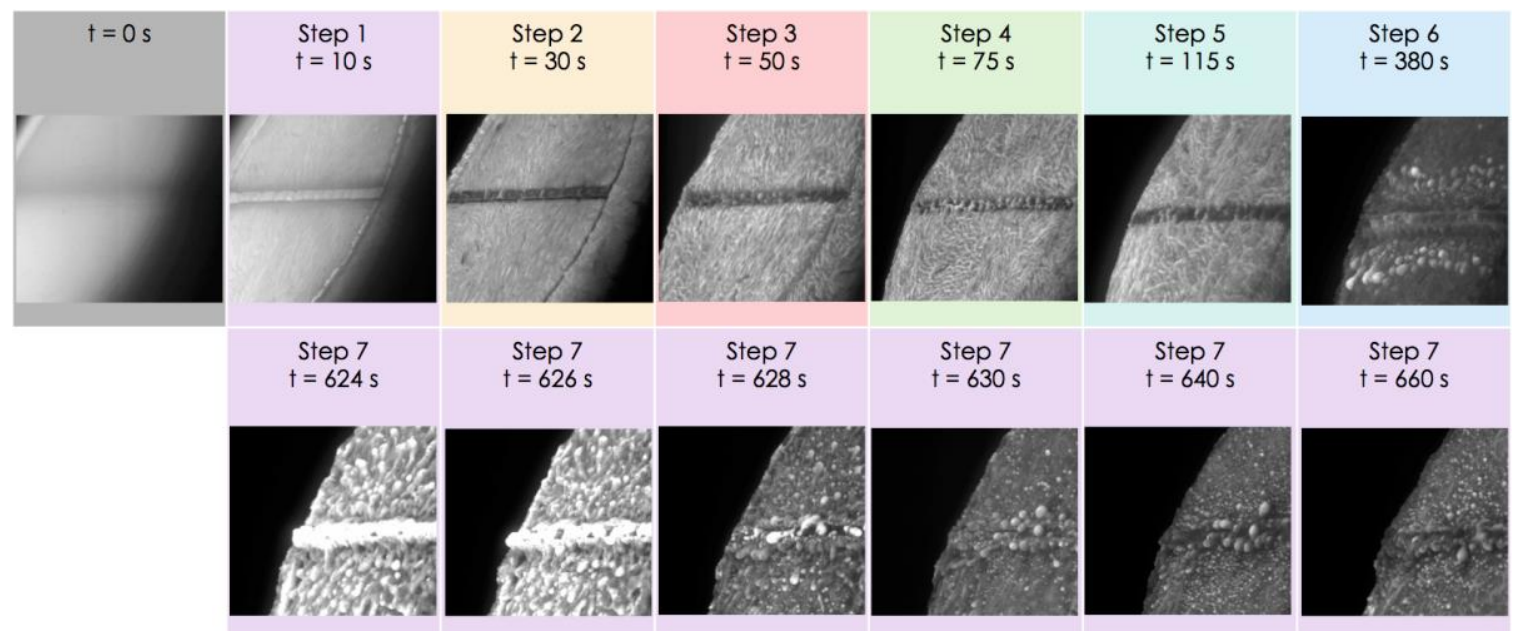

Figure 4. Video stills of EI6-1 test article demonstrating progression of surface response.
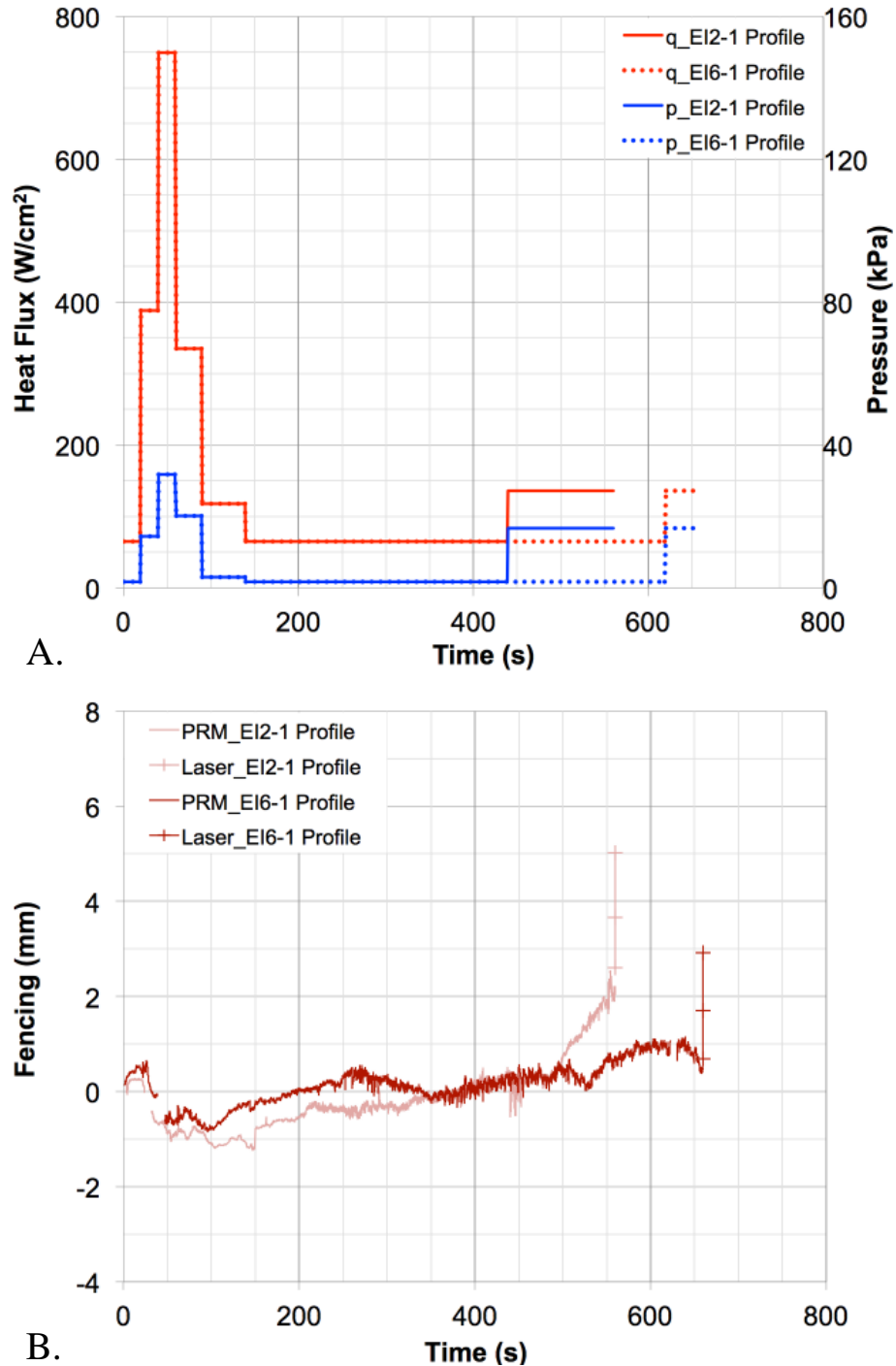

Figure 5. A. EI2-1 and EI6-1 heat flux and pressure profiles. B. EI2-1 and EI6-1 fencing profiles 


\section{Conclusions}

The proposed paper describes arc-jet test results for characterization of fencing development. PRM reveals that gapping occurs above $300 \mathrm{~W} / \mathrm{cm}^{2}$, and the presence of gapping attenuates fencing behavior. Nevertheless, in all heating profiles used for testing, the gap filler ultimately protrudes above the molded Avcoat, however, fencing never exceeds the critical fence height of $5 \mathrm{~mm}$ that would induce a turbulent transition.

Furthermore, this work portrays the current transient arc-jet testing capabilities and complimentary surface measurement capabilities at NASA ARC. Together these abilities enabled the completion of experimental work that is imperative for understanding the updated Orion TPS architecture, and surely time-varying arc-jet testing can create valuable learning opportunities for future programs and projects to come.

\section{Acknowledgments}

The authors gratefully acknowledge the support provided by the Orion TPS Insight and Oversight Project and NASA ARC Entry Systems and Technology Division through their contract NNA15BB15C to ERC Incorporated and AMA Incorporated. The authors would also like to thank the PRM team and arc jet test facility team at Ames and NASA-SCAP for their critical financial support of the arc jet operational capability at Ames.

\section{References}

${ }^{1}$ Cichan, T., Norris, S.D., and Marshall, P.F., "Orion: EFT-1 Flight Test Results and EM-1/2 Status," AIAA Paper 2015-4414, August 2015.

${ }^{2}$ Balboni, J.A., Gökçen, T., Hui, F.C.L., Graube, P., Morrissey, P., and Lewis, R., “Consolidating NASA's Arc Jets,” AIAA Paper 2015-2667, June 2015.

${ }^{3}$ Schairer, E.T. and Heineck, J.T., "Photogrammetric Recession Measurements of Ablative Materials in the NASA Ames Sixty-Megawatt Arcjet," IEEE 1-4244-1600, 2007.

${ }^{4}$ Gökçen, T., Balboni, J. A., and Alunni, A. I. "Computational Simulations of the 10-MW TP3 Arc-Jet Facility," AIAA Paper 2015-3103, June 2015. 